\title{
ZUHUD DALAM PANDANGAN IBNU TAIMIYAH
}

\author{
Rif'at Husnul Ma'afi \& Muhammad Fahmi
}

Universitas Darussalam (UNIDA) Gontor

\begin{abstract}
Abstrak:Manusia hidup di alam dunia tidak terlepas di antara dua hal, yaitu bahagia dan sengsara. Semua manusia yang berakal berkeinginan untuk mendapatkan kebahagiaan. Namun sayangnya, banyak di antara mereka yang salah dalam menafsirkan kebahagiaan yang hakiki. Banyak yang beranggapan, kebahagiaan diperoleh dengan cara mengumpulkan harta yang banyak dan melampiaskan nafsu syahwat. Padahal, sikap yang demikian justru membuat mereka mengalami kekosongan batin, karena yang diperoleh adalah kebahagiaan semu. Di sisi lain, ada sekelompok orang yang menghabiskan waktunya dalam beribadah total kepada Allah tanpa memperhatikan kebutuhan hidupnya. Mereka beranggapan bahwa pekerjaan duniawi akan membuat mereka melupakan akhirat. Pada akhirnya mereka membuat pengakuan, bahwa perilakunya merupakan manifestasi dari sikap zuhud. Berdasarkan fenomena inilah akhirnya Ibnu Taimiyah mencoba meluruskan pemahaman yang salah tersebut, yaitu dengan mengembalikan pemahaman yang benar terhadap zuhud serta sesuai dengan ajaran al-Qur'an dan al-Hadits. Dalam konsepnya dijelaskan bahwa perilaku zuhud dilakukan dengan meninggalkan segala yang tidak ada manfaatnya di akhirat dan berpegang teguh kepada hukumhukum Allah. Baginya perilaku seorang yang berzuhud (zahid) lebih penting daripada teori-teori yang banyak disampaikan oleh ulama-ulama, karena Ibnu Taymiyah tidak terlalu membeda-bedakan konsep zuhud antara ulama yang ada. Ibnu Taymiyah juga menjelaskan tentang buktibukti bahwa seseorang telah berzuhud, menjelaskan maqam zuhud dalam ilmu tasawwuf, hingga jalan yang perlu dicapai untuk menuju derajat zuhud. Baginya zuhud terbagi menjadi dua, yaitu zuhud yang disyariatkan dan zuhud yang tidak disyariatkan. Melalui tulisan ini akan dijelaskan lebih lanjut konsep zuhud menurut Ibnu Taymiyah.
\end{abstract}

Kata Kunci: Zuhud, Ibnu Taymiyah, Bukti seseorang telah berzuhud, Zuhud yang disyariatkan, Zuhud yang tidak disyariatkan. 


\section{الزهد عند ابن تيمية}

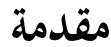

إن الإنسان يستطيع أن يكتسب محبّة الله تعالى بالزهد في الدنيا لأن الله

سبحانه وتعالى يحبّ من أطاعه، ويكتسب محبة الناس بالزهد فيما في أيديهم،

لأغم يحبون من عفّ عنهم و لمن زهد فيما في أيديهم، هناك الحديث روي عَنْ

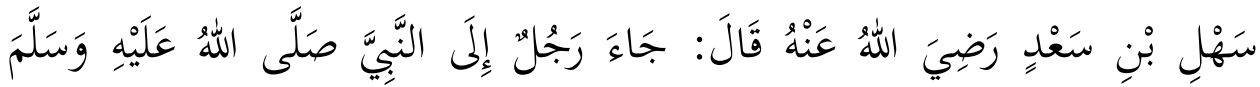

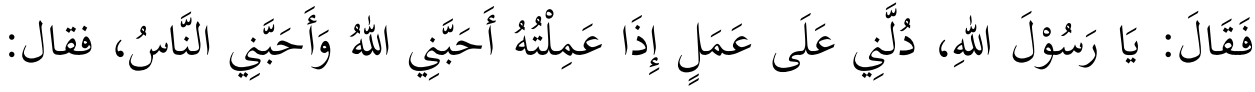

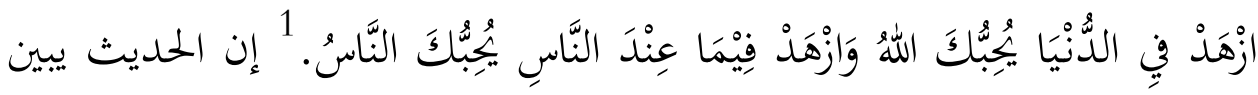
عن اكتساب محبة الله و الناس بطريقة الزهد.

1 الحافظ ابن حجر العسقلاني، بلوغ المرام من أدلة الأحكام، الطبعة الأولى، (جاكرتا: دار الكتب الإسلامية، 2002)، ص. 345. 
ومعنى الزهد في اللغة: الزاي والهاء والدال أصل يدل على قلة الشيء، والزهيد: الشيء القليل، و ولا يقال الزهد إلا في الدين خاصة، والزهد ضد الرغبة والحرص على الدنيا، ${ }^{3}$ قال بعض العلماء كعبد الله بن المبارك: الزهد هو الثقة بالله تعالى مع حب الفقر، ${ }^{4}$ وقال عبد الواحد بن زبد: الزهد ترك الدينار والدرهم، 5 ويرتبط لفظ الزهد عند الصوفية بالفقر، قال الحسن البصري: الزهد في الدنيا يريح القلب والبدن، أي جعل القلب والبدن يستريحان من أعمال الدنيا، وقال الغزالي في الزهد هو ترك الدنيا للعلم بحقارتا بالإضافة إلى نفاسة الآخرة. 7 22 سعاد الحكيم، المعجم الصوفي الحكمة في حدود الكلمة، الطبعة الأولى، (بيروت: دنداة

$$
\text { للطباعة والنشر، 1981)، ص. }
$$

3 ابن منظور، لسان العرب، البجلد الثالث، (القاهرة: دار المعارف، 1981 1119)، ص. 1876.

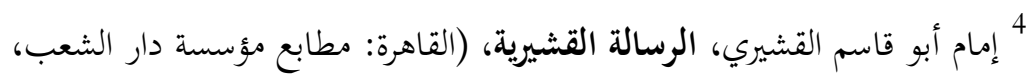

$$
\text { 1989)، ص. 220. }
$$

6 ع عبد الله بن المبارك المروزي، الزهد و الرقائق الجلد الأول، الطبعة الأولى، (الرياض:

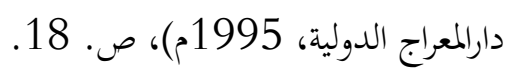

7 الإمام الغزالي، إحياء علوم الدين، الجزء الرابع، (سماراغ: مكتبة و مطبعة كريا طه فوترا،

$$
\text { دون السنة) ص. } 211
$$


ومن الظاهر بين الناس فهمان متعاكسان عن الزهد، فالأول الفهم الذي

يجث على التطرف في ترك الدنيا مطلقا، والثاني الفهم الذي يجرّ على ركوب الدنيا أي لايترك الدنيا مطلقا بل جعل الدنيا وسيلة لأجل الآخرة. ثم جاء أحد تلاميذ ابن تيمية هو ابن قيم الجوزية، يقول في كتابه: "وقد أكثر الناس من الكلام في الزهد وكل أشار إلى ذوقه، ونطق عن حاله وشاهده، فإن غالب عبارات القوم عن أذواقهم وأحوالهم، والكلام بلسان العلم أوسع من الكلام بلسان الذوق، وأقرب إلى الحجة والبرهان"، وسمعت شيخ الإسلام ابن تيمية يقول: "الزهد ترك ما لا ينفع فن الآخرة"، وهذه العبارة من أحسن ما قيل في الزهد، 9 فهذا هو السبب الذي يدعو الباحث إلى البحث العلمي في آراء ابن تيمية وأقواله في الزهد.

8 ابن قيم الجوزية، مدارج السالكين بين منازل إياك نعبد و إياك نستعين، الجزء الأول،

$$
\begin{aligned}
& \text { (بيروت: دار الفكر، 1412)، ص. } 9 . \\
& \text { 9 نفس المرجع، ص. 1412، ص. } 10 .
\end{aligned}
$$




\section{ترجمة حياة ابن تيمية}

الاسم الكامل من شيخ إسلام ابن تيمية هو الشيخ أحمد تقي الدين أبو

العباس بن الشيخ شهاب الدين عبد الحليم بن الشيخ بمدِ الدين أبى البركاتِ بن

عبد الله بن تيميَّة. 10

الأب من ابن تيمية هو الشيخ شهاب الدين وأمّا جلده الشيخ ججُُ الدين

أبو البركات عبد السلام بن عبد الله بن تيمية الحرّاّي، وُلد ابن تيمية من أسرة

العلماء المتمسكين بمنهج السلف لأن أباه كان عالما محدثا وفقيها حنبليا وجده من كبار علماء الحنابلة فسلك ابن تيمية منهجه في السلف بما سلك به أبوه وجده.

من سبب تسميته بابن تيمية بأن جده ذهب إلى الحج وكانت امرأته حاملا فلما كانت بتيماء رأى طفلة جميلة فلما رجع، وجد امرأته قد وضعت بنتا 10 أبي عبد الله هُمَّمَ بن سعيد بن رسلان، حول حياة شيخ الإسلام ابن تيمية، الطبعة

$$
\begin{aligned}
& \text { الثانية، (مصر: مكتبة المنار، 2002)، } 6 . \\
& \text { نه نفس المرجع، } 7 .
\end{aligned}
$$


فلما رآها قال: يا تيمية، أي أها تشبه الطفلة التي رآها بتيماء، فلقب شيخ

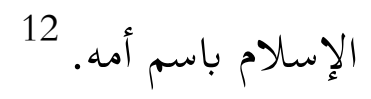

وُلد شيخ الإسلام ابن تيمية في يوم الاثنين العاشر (10) من شهر ربيع الأول سنة إحدى وستين وستمائةٍ (661هـ) 13، ويذكر البعض الآخر أن مولده في الثاني عشر من شهر ربيع الأول، وهناك من أورد التارخين معا، والله تعالى أعلم 14، ومولده بمدينة حرّان 15 اشتغل شيخ الإسلام في صغره بحفظ الحديث والفقه واللغة العربية وكان قد ختم القرآن صغيرا، وأول كتاب حفظه في الحديث هو الجمع بين الصحيحين للإمام الحميدي 16، وكان شيخ ابن تيمية أحد العلماء المتواضع، رحيم القلب للفقير الصالح ويكرمه وأنه لا يسأم من يسأله وكان سخياً

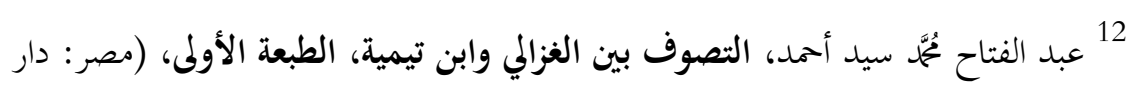

$$
\begin{aligned}
& \text { الوفاء، 1420ه)، } 188 .
\end{aligned}
$$

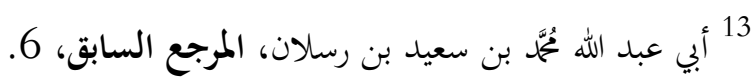

$$
\begin{aligned}
& \text { 14 } 14 \\
& 15 \\
& \text { 16 نفس المرجع، 12-13 المرجع، 6. }
\end{aligned}
$$


جواداً، ويجود ويعطي بكل ما يستطيع حتى ولو يشاطره بعض لباسه الذي عليه.

اشتغل ابن تيمية في حياته بعبادة الله بقراءة القرآن الكريم وإقامة

العبادات الليلية والنهارية وإذا رأى منكرا في طريقه أزاله، أو سمع بجنازة سارع إليها للصلاة عليها وكان قانعا بما في يده وزاهدا من الحياة الدنيوية. 18

ولقد نشر دعوات متعددة إلى الدين الإسلامي حتى أدخله الناس إلى

السجن وتوفي فيه في ليلة الاثنين لعشرين من ذي القعدة سنة ثمان وعشرين

$$
\text { وسبعمائة (728) من الهجرة النبوية } 19 .
$$

17 ابن تيمية، الفتوى الحمية الكبرى، الطبعة الثانية، (الرياض: دار الصميعي، 1425هـ)،

18 ابن تيمية، الإخنائية أو الرّّد على الإخنائي، الطبعة الأولى، (جدة: دار الخراز،

(1420هـ)، 27

19 ابن تيمية، الفتوى الحمية الكبرى، المرجع السابق، 35. 


\section{منهجه ومؤلّفاته}

ابن تيمية له منهج خاص في فكره وهو، الأول عدم الثقة بالعقل في

الأحكام والعقائد، الثاني عدم اتباع الرجل ويتبع القرآن والسنة، الثالث لايتبع

أحد بعد الرسول إلا الصحابة وأحيانا إلى أقوال التابعين، والرابع عدم التعصب

$$
\text { على التفكير الشخصي } 20 .
$$

وذكر التاريخ أن الشيخ ابن تيمية سمع وتعلم وأخذ العلوم من شيوخه

كثيرين يتجاوز عددهم المائتين، ومن هؤلاء الشيوخ: الشيخ زين الدين أحمد بن

عبد الدايم بن نعمة المقدسى، وابن أبي اليسر، والمجد بن عساكر، والجمال يهيى

بن الصيرفي، والقاسم الأريلي، وأبي القاسم بن علان، وأحمد بن شيبان، وأشهر

شيوخه غير ذلك هو موفق الدين قدامة المقدسى، ومن أساتذته أيضا نور الدين

$$
\text { الكتاب العربي، 1985م )، الجميلي، مناظرات ابن تيمية مع فقهاء عصره، الطبعة الأولى، (بيروت: دار }
$$


بن علي بن عبد البصير المالكي وكان لمم الأثر الطيب في تكوينه العلمي فكان مؤلفا بارعا وخطيبا مفوها ومدرسا ناجحا. بعد أن نال العلوم والدروس الكثيرة من شيوخه، علم علومه ودرسه إلى تلاميذه، ومن هؤلاء تلاميذه الذين كانوا ورثته في علمه هم: الحافظ شمس الدين مُحَّة بن قيم الجوزية ( 691-751هـ ) وهو من أشهر تلاميذه المباشرين، الحافظ المؤرخ شمس الدين أبو عبد الله يُمَّم الذهبي ( ت 748هـ )، الحافظ عماد الدين إسماعيل بن كثير البصري ( 701-774هـ )، الحافظ شمس الدين أبو عبد الله مُحُمّم بن عبد الهادى المقدسي، وكثير غير هؤلاء تتلمذ على شيخ الإسلام ابن تيمية. وقبل وفاته لقد ألف شيخ الإسلام ابن تيمية كتبا كثيرة ورسائل متنوعة التي أثرها عند طلاب العلم والمعرفة، من هذه الكتب والرسائل فيما يأتي: 23

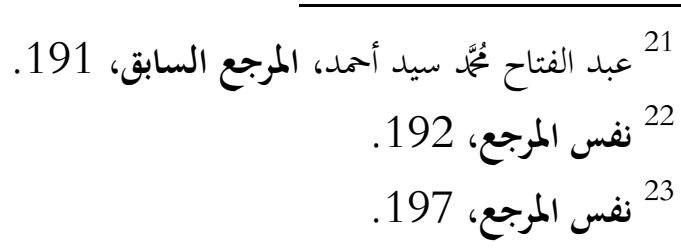


1. علوم القرآن والتفسير: التباين في نزول القرآن، تفسير سورة الإخلاص،

$$
\text { تفسير سورة النور. }
$$

2. الفقه وأصوله: مجموعة الفتاوى الكبرى، كتاب في أصول الفقه، القواعد

النورانية، رسالة في رفع الحنفي يديه في الصلاة، كتاب الفرق المبين بين

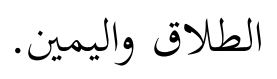

3. التصوف: الفرقان بين أولياء الرحمن وأولياء الشيطان، أمراض القلوب

وعلاجها، التحفة العراقية في أعمال القلوب، العبودية، درجات اليقين،

$$
\text { بغية المرتاب. }
$$

4. أصول الدين: رسالة أصول الدين، رسالة في القضاء والقدر، رسالة في

الاحتجاج بالقدر، كتاب الإيمان، جواب أهل العلم والإيمان، الفرقان

بين الحق والباطل، الرد على النصيرية، شرح العقيدة الأصفاهنية.

5. الرد على أصحاب الملل: الجواب الصحيح لمن بدل دين المسيح. 
6. المنطق والفلسفة: الرد على المنطقيسين، نقض المنطق، الصفدية، الرسالة

$$
\text { العرشية. }
$$

7. الأخـاقت والسياسية والاجتمـاع: الحسـنة والسيئة، الحسبة في الإسـلام،

المظالم المشتركة. وغيرها من المؤلفات الكثيرة.

بهذا يتبين للباحث بأن ابن تيمية متبحر في العلوم التمنوعة وذلك

بمؤلفاته المختلفة من العلوم، فأيضا هو عالم علامة شهير فذلك بمجموع الشيوخ الذين جعلهم أساتيذ له، وعدد ليس بقليل من تلاميذه الذين يكونون نجوما لزمانه.

\section{مفهوم الزهد عند ابن تيمية}

الزهد عند شيخ الإسلام ابن تيمية ضد من الرغبة، وهو كالبغض

المخالف للمحبة، والكراهة المخالفة للإرادة، 24 الزهد خلاف الرغب، يقال:

فلان زاهد في كذا، فلان راغب فيه، والرغبة هي من جنس الإرادة، فالزهد في

$$
\text { 1418 ابن تيمية، المستدرك على مجموع فتاوى، المجلد الأول، الطبعة الأولى، (د.مطبعة، }
$$


الشيء معناه انتفاء أو منع أو بغض الإرادة له، إما مع وجود كراهته و إما مع عدم الإرادة و الكراهة، بجيث لا يكون مريدًا له ولا كارهًا له، وكل من لم يرغب في الشيء ويريده فهو زاهد فيه. و كما رغب في الزهد وذم ضده في قوله تعالى: مَنْ كَانَ يُرِيْدُ الحَيَّةً

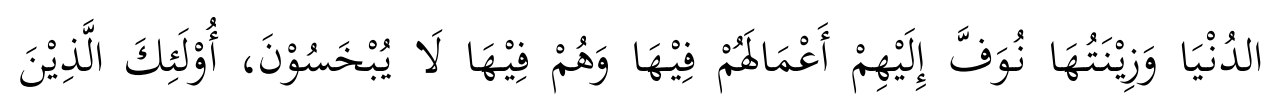

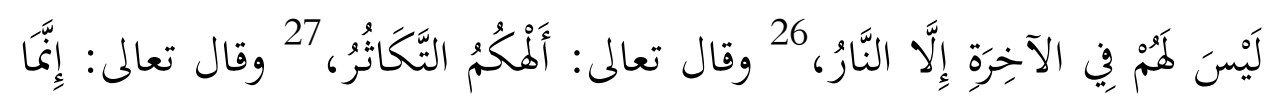

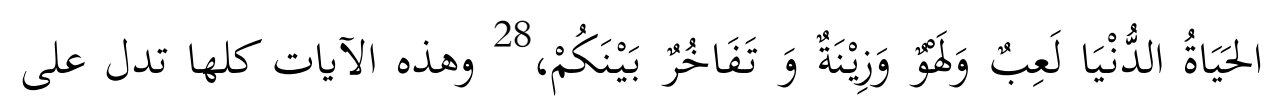
أمر في الزهد وذم وبغض في أمر ضده. والزهد ليس بمعنى الكسل والضعف، 25 25 تيمية، الزهد و الورع و العبادة، الطبعة الأولى، (مكتبة المنار، 1987م)، ص.

$$
\begin{aligned}
& 26 \text { سورة هود الآية: } 15 \text { - } 16 . \\
& 27 \text { سورة التكاثر الآية: } 1 . \\
& 28 \text { سورة الحديد الآية: } 20 .
\end{aligned}
$$


وأيضًا معنى الرغبة أو الإرادة ليس بمعنى الحرص والطمع بل إذما تعريف خاص

$$
\text { وليس سواء. }
$$

إن شيخ الإسلام ابن تيمية يرى أن الواجبات والمستحبات لا يصلح

فيها زهد ولا ورع، وأما المحرمات والمكروهات فيصلح فيها الزهد والورع، وأما

$$
\text { المباحات فيصلح فيها الزهد دون الورع. }
$$

حقيقة مفهوم الزهد عند شيخ الإسلام ابن تيمية هو ترك كل شيء لا

ينفع في دار الآخرة، وثقة القلب بما عند الله، كما في الحديث الذي رواه

الترمذي: ليس الزهد في الدنيا بتحريم الحلال، ولا إضاعة المال، ولكن الزهد أن

تكون بما في يد الله أوثق بما في يدك، وأن تكون في ثواب المصيبة إذا أصبت

أرغب منك فيها لو أهما بقيت لك، لأن الله تعالى يقول في القرآن الكريم: لِكَيْلاً

29 ابن تيمية، مجموع الفتاوى، البجلد العاشر، (المدينة المنورة: مكتبة الملك فهد الوطنية،

1425هـ)، ص. 617.

10 30 صن تيمية، بجموع الفتاوى المجلد العاشر، المرجع السابق، ص. 617. 
تَأْسَوْا عَلَىلى مَا فَانَكُمْ وَلَا تَفْرَحُوْا بِمَا عَاتَكُمْهُ 31 أي قد دعا الناس إلى أن لا ييأسوا على ما فاتم من الدنيا، ومن المعلوم أن الحزن على الدنيا أولى بأن ينهي عنه من الحزن على الدين، 32 فهذا صفة القلب. 33 وإن ابن تيمية لا يهتم بالفروق بين ألفاظ الفقر والزهد والتصوف، ذلك لأن المهم عنده هو العمل وليس مجرد الشعارات والألفاظ، فإذا كانت تدل على طريق العبادة والعمل فإن هذا الطريق يصبح صحيحا إذا اتفق مع الشرع، كما كان يسلكه الأوائل، وينحرف إذا ما ابته في طريق مخالف للشرع، 34 يقول ابن

$$
31
$$

32 ابن تيمية، تفسير شيخ الإسلام ابن تيمية، الجزء السادس، الطبعة الأولى، (المملكة

$$
\text { العربية السعودية: دار ابن الجوزي، 1432هـ) ص. } 207 .
$$

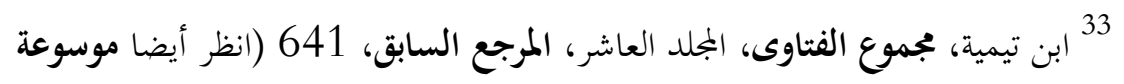

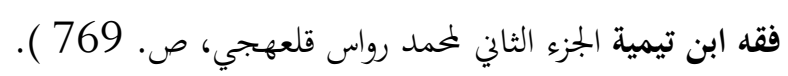

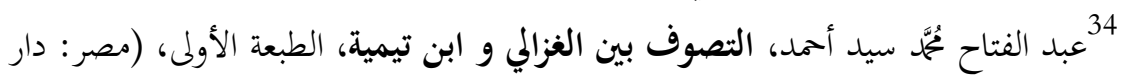

$$
\text { الوفاء، 1420هـ)، ص. } 208 .
$$


تيمية: "وأولياء الله هم المؤمنون المتقون"، سواء سمي أحدهم فقيرا أو صوفيا أو فقيها أو عالما أو تاجرا أو صانعا أو أميرا أو حاكما أو غير ذلك. 35

أدلة الزهد

أدلة الزهد عند ابن تيمية تقوم على أمرين، هما:

الأول، ترك الزاهد فضول المباحات لأغا مناقضة للزهد، 36 وبالجملة أن

الأفعال التي يمكن دخولها تحت الأمر والنهي لا تكون مستوية من كل وجه، بل إن فعلت على الوجه المحبوب كان وجودها خيرًا للعبد، و إلا كان تركها خيرًا له

و إن لم يعاقب عليها، ففضول المباح التي لا تعين على الطاعة عدمها خير من

1425 ابن تيمية، مجموع الفناوى، البجلد الحادي عشر، ( مكتبة الملك فهد الوطنية، المدينة

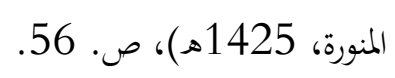

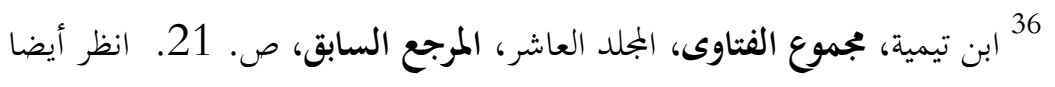

$$
\text { موسوعة فقه ابن تيمية الجزيء الثاني لمحمد رواس قلعهجي، ص. } 769
$$


وجودها، إذا كان مع عدمها يشتغل بطاعة الله، فإنها تكون شاغلة له عن ذلك، و أما إذا قدر أهما تشغله عما دونا فهي خير له مما دوها. 37 الثاني، ترك الزاهد من الأفعال ما لا ينفع في الآخرة، أي ترك ما لا ينفع في الآخرة، فأما ينفع في الآخرة وما يستعان به على ذلك، فالزهد فيه نوع من عبادة الله و طاعته، والزهد إنما يراد ذلك لأنه فيما يضر، أما الدنيا لا حمد فيه، كما لا ذم على الرغبة فيها، إنما الحمد على إرادة الآخرة، والذم على إرادة الدنيا المانعة من خير الآخرة، وبناء على ذلك فإن الدنيا إن كانت لا تشغل عن الآخرة لم يشرع الزهد فيها، 38 وعلى هذا فإن الزهد لا يلازمه الفقر، فقد يكون المرء غنيًا زاهدا، 39 والمطلوب من الغني الزاهد أن يكون حاكما للدنيا وليس

$$
\text { 38 نفس المرجع، ص. } 461 .
$$

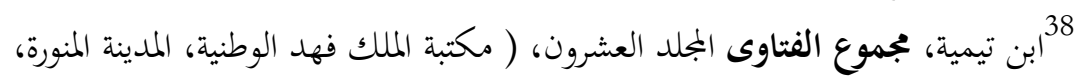
1425هـ)، ص. 146. 1931 تيمية، 146، مجموع الفتاوى المجلد الحادي عشر، المرجع السابق ، ص. 28. 
محكوما بها، يسخرها لقضاء حاجته، وكان إخراج فضول المال والاقتصاد على الكفاية أسلم وأنفع في الدنيا والآخرة.

\section{مقام الزهد في التصوف}

هؤلاء الفقراء قد يكون فيهم من هو أفضل من كثير من الأغنياء، وقد

يكون من الأغنياء من هو أفضل من كثير منهم، وقد تنازع الناس أيما أفضل: الفقير الصابر أو الغني الشاكر؟ الصحيح أن أفضلهما أتقاهما: فإن استويا في التقوى استويا في الدرجة، كما قد بيناه في غير هذا الموضوع، فإن الفقراء يسبقون الأغنياء إلى الجنة، لأنه لا حساب عليهم، ثم الأغنياء يحاسبون، فمن كانت حسناته أرجح من حسنات فقير، كانت درجته في الجنة أعلى، وإن تأخر عنه في الدخول، ومن كانت حسناته دون حسناته كانت درجته دونه، 40ف 10 المرجع، ص. 107. 
لكن لما كان جنس الزهد في الفقراء أغلب، صار الفقر في اصطلاح كثير من

$$
\text { الناس عبارة عن طريق الزهد وهو من جنس التصوف. } 41
$$

فالسالك طريق الفقر والتصوف والزهد والعبادة، إن لم يسلك بعلم يوافق

الشريعة، وإلا كان ضالا عن الطريق، وكان ما يفسده أكثر مما يصلحه،

والسالك من الفقه والعلم والنظر والكلام إن لم يتابع الشريعة ويعمل بعلمه وإلا

كان فاجرا ضالا عن الطريق، فهذا هو الأصل الذي يجب اعتماده على كل

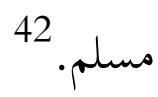

وفي كتاب آخر يقال إن الزهد يدخل إلى الصوفية الحقيقيين، وهم عند

ابن تيمية من تفرغ للعبادة والزهد في الدنيا، وهم الذين يرون أن الصوفي من

صفا من الكدر وامتلأ من الفكر، واستوى عنده الذهب والحجر، وهذا الصنف

من الصوفية هو الذي ارتضاه ابن تيمية وسار عليه، ويقول عن هذا الصنف

الصوفي: "هو في الحقيقة نوع من الصديقين، فهو الذي اختص بالزهد والعبادة

$$
\text { 42 نفس الممجع، ص. } 21 \text { صنسع، } 21 .
$$


على الوجه الذي اجتهد فيه، فهو أخص من الصديق المطلق ودون الصديق الكامل الصديقيون من الصحابة والتابعين و تابعيهم". 43

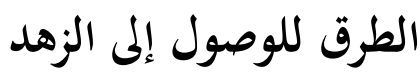

الطريق للوصول إلى ذلك عند ابن تيمية هو الاجتهاد في فعل المأمور

وترك المخظور والاستعانة بالله على ذلك، فمن فعل ذلك وصل إلى حقيقة

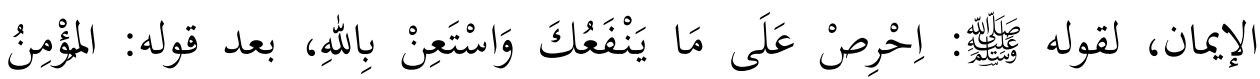

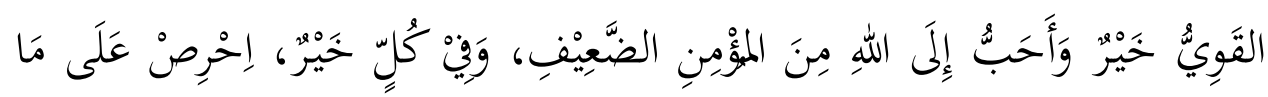

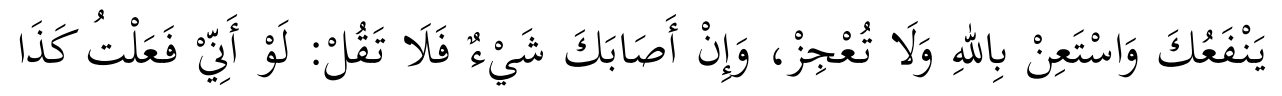

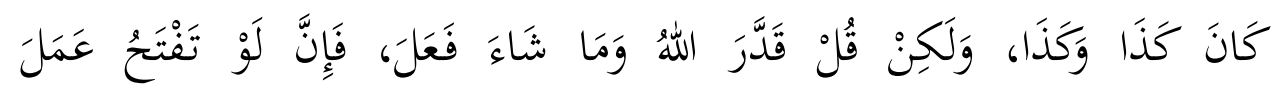
الشَنَطَْانِ.

43 نفس المرجع، 19، انظر أيضًا عبد الفتاح يُّمّ سيد أهمد، المرجع السابق، ص.

.203

44 4بن تيمية، المستدرك على مجموع الفتاوى، الجملد الأول، المرجع السابق، ص. 162. 
استبط الباحث أن الطريق للوصول إلى الزهد هي بالعلوم النافعة إلى خير

الدنيا والآخرة لكي يسلك الزاهد في الطرق الموصلة إلى مقصده وتوصله إلى

مطلوبه، ولنيل العلوم النافعة في الدنيا والآخرة لابد من الزاهد الاستعانة بالله،

وعندما استعانته بالله فلا تترك العمل وإهمال القيام بالأسباب الموصلة إلى

المطلوب، ولا تقول لو في تأدية أعماله اليومية إلا التمني الخير، أو في بيان العلم

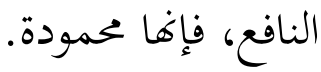

وطريق آخر للوصول إلى الزهد يقول ابن تيمية:" لا يجصل الإخلاص إلا

بعد الزهد، ولا زهد إلا بتقوى، والثقوى متابعة الأمر والنهي"، 45 عرف

الباحث، هناك طريق للوصول إلى الزهد من كتاب آخر، فهو الأمر بالمعروف

والنهي عن المنكر، ومن المعلوم إذا أراد العبد بالأمر والنهي في الشريعة سوف

ظهر عليه الفتنة، ومن صبر على ذلك سوف يعمل الزهد من الدنيا ولكن لا

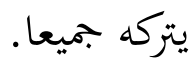

15 ابن تيمية، مجموع الفناوى، الجلد الأول، (المدينة لمنورة: مكتبة الملك فهد الوطنية،

$$
\text { 1425هـ)، ص. } 94 .
$$




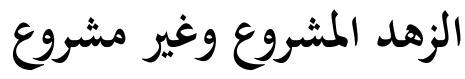

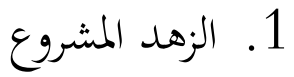

الزهد النافع المشروع الذي يحبه الله ورسوله هو الزهد فيما لا ينفع في

الآخرة، فأما ينفع في الآخرة وما يستعان به على ذلك فالزهد فيه نوع من عبادة

الله وطاعته، والزهد إنما يراد ذلك لأنه فيما يضر، أو زهد فيما لا ينفع، فأما

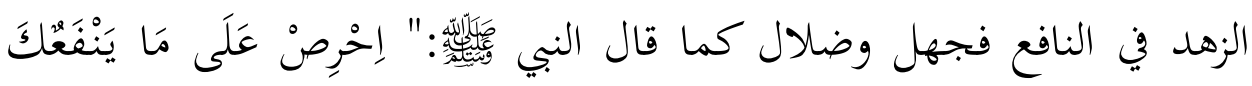

$$
\text { وَاسْتَعْنْ بِاللهِ وَلَا تُعْجِز ". } 46
$$

والنافع للعبد هو عبادة الله تعالى وطاعة رسوله، وكلما صده أو يعارضه

عن ذلك فإنه ضار لا نافع، ثم الأنفع له أن تكون كل أعماله عبادة الله وطاعة

له، وإن أدى الفرائض وفعل مباحا لا يعنيه على الطاعة فقد فعل ما ينفعه وما

لا ينفعه ولا يضره.

46 46 تيمية، ججموع الفناوى، المجلد العاشر، المرجع السابق، ص. 511.

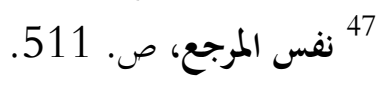


الزهد المشروع كذلك ترك ما لا ينفع في الدار الآخرة، وأما كل ما يستعين

به العبد على طاعة الله فليس تركه من الزهد المشروع بل ترك الفضول التي تشغل عن طاعة الله ورسوله هو المشروع. 48

أن حقيقة من الزهد المشروع عند شيخ الإسلام ابن تيمية هو أن يكون

بغضه وحبه وزهده فيه أو عنه تابعًا لحب الله وكراهته، فيحب ما أحبه الله،

ويبغض ما أبغض الله، ويرضى ما يرضاه، ويسخط ما يسخطه، بحيث لا يكون

تابعًا لمواه بل لأمر مولاه. فإن كثيرا من الزهاد في الدنيا أعرضوا عن فضولمم و لم يقبلوا على ما يبيحه الله ورسوله، وليس هذا الزهد هو الذي أمر الله به، ولهذا كان في المشركين زهاد، وفي كل أهل الكتاب زهاد وفي كل أهل البدع زهاد. 49

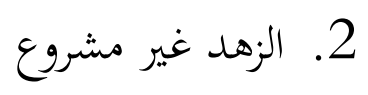

وأما الزهد غير مشروع عند شيخ الإسلام هو أن يزهد فيما أمر الله به ورسوله أي أن يزهد فيما لا يحبه الله ورسوله، ويزهد فيما يرغب ما يحبه الله 48 ابن تيمية، مجموع الفتاوى، الجملد الحادي عشر، المرجع السابق، ص. 28 - 29.

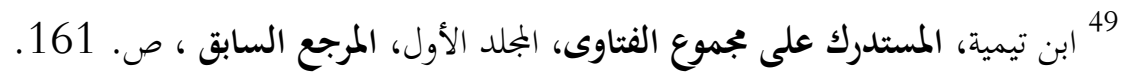




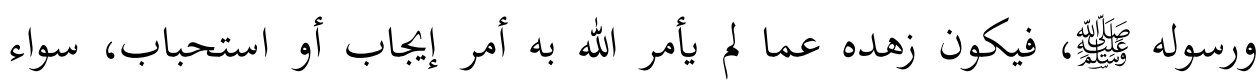
كان محرما أو مكروها أو مباحا ويكون مع ذلك مقبلا على ما أمر الله به، ولا يترك المكروه بدون فعل المحبوب، فإن المقصود بالقصد الأول فهو فعل المحبوب، وترك المكروه معين على ذلك، فتزكوا النفس بذلك، كما تزكوا الزرع إذا نقي من

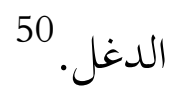
وفي كتاب آخر بيّن ابن تيمية الغلط في الزهد من وجوه كما وقع في

الأول، أن قوما زهدوا فيما ينفعهم بلا مضرة، فوقعوا به في ترك واجبات

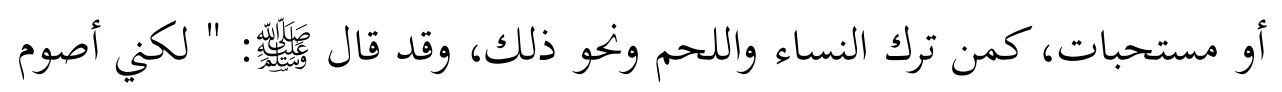
و أفطر وأتزوج النساء، وأكل اللحم، فمن رغب عن سنتي فليس مني".

$$
\text { نفس المرجع، ص. } 162
$$

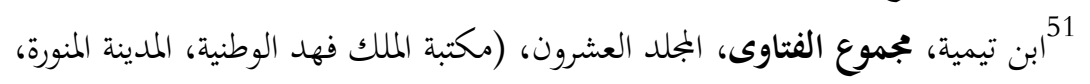

$$
\text { 1425هـ)، ص. } 150 .
$$


الثاني، أن الزهد هذا أوقعه في فعل المخظورات، كمن ترك تناول ما أبيح له من المال والمنفعة، واحتاج إلى ذلك فأخذه من حرام، أو سأل الناس المسألة الخحرة، أو استشرف إليهم، والاستشراف مكروه.

الثالث، من زهد زهد الكسل والبطالة والراحة، لا لطلب الدار الآخرة

بالعلم الصالح والعلم النافع، فإن العبد إذا كان زاهدًا بطالا فسد أعظم فساد، فهؤلاء لا يعمرون الدنيا ولا الآخرة، كما قال عبد الله مسعود: " إني لأكره أن أرى الرجل بطالا ليس في أمر الدنيا و لا في أمر الآخرة، وهؤلاء من أهل النار". فمن ترك بزهده حسنات مأمورا بها كان ما تركه خيرًا من زهده أو فعل سيئات منهيًا عنها، أو دخل في الكسل والبطالات، فهو من الأخسرين أعمالا، الذين ضل سعيهم في الحياة الدنيا وهم يحسبون أفم يحسنون صنعًا، ومن زهد فيما يشغله عن الواجبات أو يوقعه في المحرومات فهو من المقتصدين أصحاب اليمين أي الجنة، ومن زهد فيما يشغله عن المستحبات والدرجات فهو من المقدمين السابقين، واحذر أن تغتر بزهد الكافرين والمبتدعين، فإن الفاسق المؤمن 
الذي يريد الآخرة ويريد الدنيا خير من زهاد أهل البدع وزهاد الكفار، إما لفساد عقدقم وإما لفساد قصدهم وإما لفسادهما جميعًا. 52

الخاتمة

على حسب ما قد حصل عليه الباحث في بحثه، يأتي الباحث بعده بما لايقل منه أهمية وهو بعض النقط التي تلزم رعايتها والاهتمام بها، الأول ينبغي لكل مسلم أن يهتم أن الزهد هو إحدى العبادات التي يحثها القرآن والسنة ليكتسب المحبة من الله ومن الناس، الثاني ينبغي لكل مسلم أن يتنبه في إتيان معنى الزهد وموقفه في الدين لئلا يخطئ في العمل ولايَضل ولايُضل من حوله. وبهذا يعيش المسلم عيشة بسيطة راضية مرضية مطمئنة في الدنيا وسعيدة في الآخرة و الله الموفق إلى أقوم الطريق والحمد لله رب العالمين. مصادر البحث

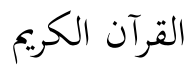
$\overline{.52}$ 
تيمية، ابن. 1987. الزهد و الورع و العبادة. الطبعة الأولى. د. م: مكتبة المنار.

1418هـ. المستدرك على ججموع فتاوى. المجلد الأول. الطبعة الأولى.

1432هـ. تفسير شيخ الإسلام ابن تيمية. الجزء السادس. الطبعة الأولى.

المملكة العربية السعودية: دار ابن الجوزي.

1425هـ. مجموع الفتاوى. المجلد العاشر. المدينة المنورة: مكتبة الملك فهد

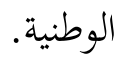

1425هـ. مجموع الفتاوى. المجلد الحادي عشر. المدينة المنورة: مكتبة الملك.

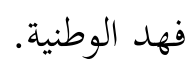

1425هـ مجموع الفتاوى. المجلد العشرون المنورة: مكتبة الملك فهد الوطنية.

منظور، ابن .1119. لسان العوب. المجلد الثالث. القاهرة: دار المعارف.

الإمام، الغزالي. د.س. إحياء علوم الدين. الجزء الرابع. سماراغ: مكتبة و مطبعة كريا طه

فوترا. 
الحكيم، سعاد. 1981. المعجم الصوفي الحكمة في حدود الكلمة. الطبعة الأولى. بيروت: دنداة للطباعة والنشر.

الجوزية، ابن قيم. 1412 مدارج السالكين بين منازل إياك نعبد و إياك نستعين. الجزء الأول. بيروت: دار الفكر.

العسقلاني، الحافظ ابن حجر. 2002. بلوغ المرام من أدلة الأحكام. الطبعة الأولى.

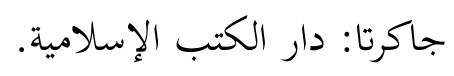

القشيري، إمام أبو قاسم. 1989. الرسالة القشيرية. القاهرة: مطابع مؤسسة دار

المبارك المروزي، عبد الله بن. 1995م. الزهد و الرقائق. المجلد الأول. الرياض: دارالمعراج

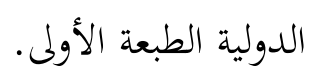

مُحّمّ سيد أحمد، عبد الفتاح. 1420هـ التصوف بين الغزالي و ابن تيمية. الطبعة الأولى.

$$
\text { مصر: دار الوفاء. }
$$

